Discourse and Communication for Sustainable Education, vol. 10, no. 1, pp. 81-90, 2019

\title{
Scenarios of a Sustainable E-leadership for Thai Higher Educational Institution Leaders in 2027
}

\author{
Kittiya Sathithada and Poschanan Niramitchainont \\ Mahidol University, Phuttamonthon, Thailand
}

\begin{abstract}
E-leadership has not been thoroughly explored, especially in Thai higher educational institutions. This study was conducted in a scenario planning workshop with 20 participants who were administrators, lecturers, staff members, and stakeholders of both Thai public and private higher educational institutions. The aim of this research was to develop the scenarios for Thai higher educational institution leaders to use E-leadership in 2027. The three scenarios for educational leaders to use E-leadership were developed for future Thai higher educational institutions and were e-leaders and international collaborations; e-leaders, innovation and sustainable environment; and e-leaders and the current situation. The scenarios were developed using STEEP analysis. The social aspect includes the phenomenon of youth called "digital natives", increased individual learning and society of learning, generation gap, well-educated employees, and an aging society. The technological aspect is acclimatizing to the need of users, advancing technology and innovation, technology being everywhere, and competition within technology development. The economic aspect considers increase in oil prices, investment in university, increasing numbers of cross-institutions, and rapid economic growth in ASEAN. The environmental aspect considers global warming, climate change, and redesigns learning space. Lastly, the political aspect considers government policies in education and improved environmental governance. It does not only benefit higher education, but also schools or any organization that could apply this sustainable education research to develop human resources for the future.
\end{abstract}

Keywords: E-leadership, higher education, sustainable education, scenarios of leadership, Thailand's higher education.

\section{Introduction}

Future educational leaders will face numerous issues related to the utilization of information technology. E-leaders need to be technologically literate and have great foresight when making decisions for their institutions and sustainable education. They need to be aware of their role as institution technology leaders by considering relevant instructional principles. Educational leaders must act as innovative models for their students, faculty, and staff-members to establish a new school culture. An understanding 
of distance between the leader and followers is critical to e-leadership. The best way for e-leadership to improve technology utilization is through learning and compelling everyone to use technology (Sheninger, 2014; OECD/UNESCO, 2016; Siegel \& Claydon, 2016; Hartman, Johnston, \& Hill, 2017; Svalfors, 2017). Future e-leaders would be able to make timely predictions using increase in the use of technology. To achieve sustainable development in the $21^{\text {st }}$ century through sustainable education, e-leaders should direct their energy and technology implementation within the organization toward new ways of thinking, diverse educational methods, and new educational approaches. This is because it could benefit educational management and human resources development (Fullan, 2001; Antonakis \& Atwater, 2002; Zaccaro \& Bader, 2003; Moyle, 2005; Sheninger, 2014; Ghorbani, Jafari, \& Sharifian, 2018).

Thai citizens are educated to enhance the competitiveness of the country along with the constant development of Thai higher education. Thais will have the knowledge, technology, innovation and support for sustainable development, which responds to the new era (Office of the Higher Education Commission, 2017). Thai future education leaders will face challenges associated with using information technology. The new generation of e-leaders must recognize and notice the significance of technology as well as to shape sustainable education for now and the future.

This study aims to develop scenarios for Thai higher educational institutions leaders to use e-leadership in 2027 by engaging all stakeholders. The scenario-planning workshop was conducted with 20 participants, who were administrators, lecturers, staff groups, and stakeholders of both Thai private and public higher educational institutions. The results of this study will be the first guideline for developing e-leadership in Thailand's Higher Educational Institution; and also for the Ministry of Education, Higher Education Commission, public and private universities to prepare and develop human capital that can cope with an era of technology in the future.

\section{Literature Review: E-leadership and Higher Education in Thailand}

E-leadership is defined as a type of leadership in which individuals or groups are geographically scattered, and collaboration is made possible by technology. This modern paradigm forces organizations to recognize the previous models and leaders, and to adjust and extend their leadership and virtual communications. E-leaders must possess skills that help them with management, along with being able to create a leadership panache that takes advantage of the accessible advances in technology (Avolio et al., 2009; Colfax et al., 2009). Brown \& Duguid (2000) stated that the way we work, the way we organize work, and the way we create value is fundamentally changed by information digitalization. Now, people's interactions are mediated by information technology. Consequently, the new work environment and the form of organization require a new type of leadership. E-leadership is the new type of leadership that leads to better learning results.

Currently, the education sector uses technology as a tool in organizational management; hence, education has become exponentially effective. E-leadership in educational organization needs individuals to possess technological skills and knowledge to make quality decisions for the institutions. The academic e-leaders therefore must recognize and notice the significance of technology in sustainable education, which depends on 
changing educational approaches towards challenges in the present (Franzenburg, 2016; Ghorbani, Jafari, \& Sharifian, 2018). Kearsley (1991) stated that the lack of informed leadership is one of the main barriers of integration of technology in education. Special training did not prepare principals for technology. Fortunately, it is possible to better prepare future leaders for use of technology. This means leaders need to possess critical thinking skills in order to develop both technical and human resources to cope with the digital era (Yee, 2000). Franciosi (2012) mentioned that e-leadership characteristics are critical to facilitating successful technology usage in a field founded on technological innovation and change. It yields positive results.

The Thai government is aware of the advantages of using technology in education. There are efforts made towards stimulating and supporting the use of information technology continuously for national development. The plan for education technology is to increase competencies of ICT teaching, to further increase competencies of personnel ICT capabilities, to enhance standards for e-learning materials, to improve ICT infrastructure. It includes development of ICT systems to assist management and services, to improve the quality of the higher education management towards excellence, to promote the research and development of technology and innovation for education that leads Thailand Higher Educational institutions to be Regional Research and Development Center for sustainable development, and to respond to the demand for manpower. The significance of technologies in education lies in utilizing information technology and integrating it with individual development for both education technologies developers and users. Significantly, the 2017-2021 Digital Action Plan and Digital Thailand are some examples of using technology to reduce inequality, to manage the use of digital technology in the organization to enhance the process of management practices and corporate services, and to develop human resources with knowledge about digital technology and skills for future technological changes. It is essential to develop human resources and research in correspondence to the needs of the country's development. The institution must support the development of faculty members to use technology as a learning tool that broadens learners so they can cope with technological changes. (ONEC, 1999; Office of the Higher Education Commission, 2010; Office of the Higher Education Commission, 2012; Thairath online, 2014; Office of the Secretary of the House of Representatives, 2016; Ministry of Science and Technology, 2017; Office of the Higher Education Commission, 2017).

\section{Research Question}

What are the scenarios of using e-leadership of educational leaders in Thailand's higher educational institutions in 2027 ?

\section{Methodology and the Sample}

The study was conducted using scenario planning workshop. Purposive sampling was used to select 20 participants from public and private universities in Thailand. There were five groups of participants, which were entry and middle level administrators, lecturers who teach and advise students, supporting staff, a higher educational commission officer, some students and parents. 


\section{Research Instruments}

The scenario was presented through a one-page rich contextual overview of how future research may deviate diversely. The participants were allowed to explore driving forces and future uncertainties using narratives. The researcher asked for participants' viewpoints in an expert-group workshop. The researcher conducted the process in the following order: select assumptions for changes, transport drivers into a framework, produce original mini scenarios, create three scenarios, and identify arising issues.

\section{Data Collection Process}

Developing scenarios from the rich context collection is important in designing plausible and consistent futures. The application scenario could identify the key indicators. The updated scenarios and strategies could be actively implemented.

\section{Research Findings}

Content analysis was employed to examine the data collected in this research. The scenarios for educational leaders to use e-leadership in Thai higher education in 2027 were synthesized using group discussion about scenario planning in workshop conditions. During the workshop, STEEP analysis was used. STEEP analysis was conducted for social, technological, economic, environmental, and political improvements for both individuals and educational institutions.

\section{Scenario 1: E-leaders and International Collaborations}

E-leaders in Thai higher educational institutions in 2027 need to be able to use technology to search for information, make decisions, evaluate, and solve problems. This is a result of an increase in well-educated employees, technology being everywhere, increasing numbers of cross institutions, rapid economic growth in ASEAN, government policies that encourage institutions to use technology, redesigning learning space to help facilitate the learning environment, and youths using technology in their daily lives, "digital natives". Hence, e-leaders of the future are to be skillful in acquiring technological tools and learning to use them quickly to serve young, well-educated employees that have better work abilities through using technology. Importantly, the Thai government is aware of the advantages of using technology in education. Government provides funds for technology improvement. The funds are used to develop ICT systems that support management and services that drive the quality of higher education towards excellence by developing personnel ICT competencies. E-leaders in the future will develop human resources for better work productivity and to transform basic learning processes that are fundamental to higher education. E-leaders need specific foresight to design and develop appropriate learning spaces in both virtual and actual learning environment. The emergence of the ASEAN community brings about unlimited development; and future e-leadership promotes cross-institution communication, collaboration with foreign universities, exchange students and faculty members. This is because cooperation among universities is growing in importance for future higher education. The appropriate strategies are to develop a technology system for universities, enhance learning space, develop human resources in academic settings, and improve management. 


\section{Scenario 2: E-leaders, Innovation and Sustainable Environment}

E-leaders in Thai higher educational institutions in 2027 will need to be able to use technology in a timely manner, systematically and efficiently serving the needs of stakeholders. This is due to many reasons: an increased awareness of global warming, climate change, emerging diseases, increasing the numbers of individuals learning, developing a society of learning, responding to the needs of users with technology, advancing technology and innovation, competing in technology development, increasing oil prices in recent decades, universities investing in technology for long-term development, reducing some operation processes with technology, and improving environmental governance. These E-leaders have to choose the appropriate technology for their organization and use it to make precise decisions due to technology advancement and a now highly competitive market. E-leaders in the future can use various channels of communication to reduce time, reduce cost, and save energy allowing organizations and institutions to operate more effectively. The administrators, faculties, officers, and students would also be familiar with the changes the institutions have to face as a result of technology. In order to develop a digital learning environment for a learning society, e-leaders need to learn to be prudent. They play an important role in adjusting educational setting that encourages the creative use of technologies since innovation capacity is the most crucial for competing in the $21^{\text {st }}$ century. E-leaders can help develop an awareness of reducing negative environmental impacts. They can achieve this through good governance of environmental policies in their institutions. They could also drastically change work processes in order to develop new processes that develop human resources sustainably. Suitable strategies include developing learning schemes, choosing and using technology in the organization, incorporating communication into management, providing training, working for innovation results, and setting and supporting good governance in institutions.

\section{Scenario 3: E-leaders and the Deprived Situation}

Different generations are unable to work together due to their different behavioral patterns in using technology. This is a result of the generation gaps, aging society, users' unrestrained behaviors, Thailand 4.0 Policy, and Thai education. The differences significantly affect organizational objectives through its perspectives, behaviors, and engagement. E-leaders lack technology management skills that address the generational differences that threaten relationships among employees and work. E-leaders cannot keep up with encouraging productivity in the ageing workforce and maintaining competitiveness in a digital era. They do not have efficient management skills to drive the Thailand 4.0 Policy, which focuses on modernizing and developing Thailand through innovation. E-leaders fail to make the nation benefit since they do not transform global challenges to benefit the country; Thai youth do not develop their skills; lecturers in higher educational institutions have difficulty adapting to new approaches for educating younger generations. It results in fewer students attending university. Unfortunately, the under-qualified institutions are terminated in this highly competitive era of digital challenges and globalization. Appropriate strategies to deal with this problem are to minimize the generation gap in work place through the use of technology, unify the organization, maximize learning programs for adults, and achieve Thailand 4.0 Policies. 


\section{Discussion}

Findings are significant suggestions for developing scenarios for Thai higher educational institution leaders in 2027 to use e-leadership.

\section{Scenario 1: E-leaders and International Collaborations}

It is important for educational management to perform well in this century. In order to efficiently incorporate educational technology into activities, it is important for educational leaders to keep up with the current developments in educational management; therefore, it is crucial to develop school personnel skills and their technical knowledge. Collaboration among institutions is also important for supporting administrative services and engagement. Collaboration provides professional strengths and theoretical instruction, permits coordination between faculty members to allow individual professors to focus on instruction in their areas of greatest strength and facilitate their professional development, prepares and motivates students facing obstacles that prevents them from progressing towards higher education, and encourages more transparent academic procedures in terms of international joint degree programs (Online Learning Task Force, 2011; HEFCE, 2012; Cacheiro-González et al., 2013; Carey \& Trick, 2013; EADTU, 2016b; RMIT University, 2017). In 2027, there will be international collaborations among higher educational institutions. The government supports e-leaders in universities because they can effectively manage the institution so that it would be able to use technology to develop its human resources. Both students and staff work with technological gadgets efficiently. Higher education in Thailand is the center of international education in the ASEAN region. It is achieved by developing international collaboration with Thailand as well as by developing a regional cooperation between institutions to promote the exchange of faculty, students, curricula, and research development.

\section{Scenario 2: E-leaders, Innovation and Sustainable Environment}

In 2027, e-leaders will have well-managed institutions that enable personnel and students to be more active participants in the global innovation marketplace. Various teaching methods can be implemented to communicate and develop the ability to learn in a virtual environment. The awareness of reducing negative environmental impacts is related to e-leaders who will be implementing good governance to regulate and administer environmental policies in organizations with quality technology. Besides, it directs societies effectively and efficiently aims to reduce its consumption of natural resources and also ensures a sustainable society. It requires a dynamic person who implements transformative practices and encourages development. In the 4.0 era, students are expected to learn beyond classrooms. The policy has introduced innovation that focuses on achieving sustainable growth without destroying the environment. Future Thai higher educational institutions will depend on management to help the nation overcome global challenges. Thai higher education must emphasis more on developing community networks of learning and human creativity development for innovation towards the use of technology (Miedema \& Bertram-Troost, 2015; Svalfors, 2017; Buasuwan, 2018). 


\section{Scenario 3: E-leaders and the Deprived Situation}

The use of innovative workplace practices, such as teamwork and flat hierarchies, may provide a better environment for the adoption of new technologies because of the existing complementarities. The probability of innovative practices is lower in firms that have less information-sharing and communication among management and workers. The negative effect affects workers who are over 50, meanwhile, the 40 to 55 years old members are positively linked with teamwork (Milgrom \& Roberts, 1990; Gera \& Gu, 2004). E-leaders were not successful in enriching the efficacy of university educational services and management. They also failed to transform the country through innovation. In addition, most Thai students are incapable of utilizing this new digital technology effectively since only 20 percent of students are capable of obtaining further knowledge from online media (Vanitcharearnthum, 2017). It is recommended that relevant leaders concern themselves about using education to sustainably equip students and develop all the necessary skills for themselves specific to a sustainable future. It would be ideal if leaders have the capability to accomplish sustainable institutional improvement since it could result in strong collaborative teams, collective capacity, knowledge sharing, shared authority, and continuous learning in the organization in this century (Jones \& Harris, 2014; Franzenburg, 2016).

\section{Conclusions}

The three scenarios for educational leaders to use e-leadership were developed for future Thai higher educational institutions ready to engage in international collaborations; for e-leaders using innovation and sustainable environment; and for e-leaders addressing our deprived situation. The scenarios were developed using STEEP analysis. STEEP analysis was conducted for social, technological, economic, environmental, and political improvements for both individuals and educational institutions.

The driving forces are environmental, social, technological, economic, and political. The Environmental driving force includes global warming, climate change, and redesigning learning space to help facilitate the learning environment. The Social driving force includes the younger generations using technology in daily life, often referred to as "digital native," the increasing number of individuals learning and society of learning, generation gaps, increasing numbers of well-educated employees, and the aging society. The Technological driving force means technology is everywhere, technology is able to accommodate the needs of users, advancing technology and innovation, and technology development competition. The Economic driving force includes higher oil prices in recent decades, universities investment in technology for long-term development and reducing some working processes, increasing cross-institutions, and rapid economic growth of ASEAN. Lastly, the political driving force includes government policies that encourage educational institutions to use technology and improve environmental governance.

There are three uncertainties. They are social, political, and technological uncertainties. The Social uncertainty is a result of user's unrestrained behaviors and emergence of diseases. The Political uncertainty is a result of Thailand 4.0 Policy and education. Lastly, the Technological uncertainty is a result of networking.

Obviously, leaders will gain a deeper understanding of organization experience. Leaders are essential to successful universities since their ability plays an important part in developing sustainable education and institutions, supporting academic and adminis- 
trative staff to develop their technological abilities, and creating innovative change leading to a higher rate of successful individuals (Hartman, Johnston, \& Hill, 2017).

\section{Recommendation for the Further Studies}

From this research, the author has learned that e-leadership in Thailand's higher educational institutions in 2027 is needed to progress the quality of Higher Education in Thailand. This benefits Ministry of Education, Higher Educational Institutions, Educational leaders, and stakeholders in Thailand so as to provide the development of E-leadership of future technological school leaders, providing balance in the digital environment.

E-leadership significantly impacts the educational field. The training packages for developing e-leadership are applicable and can prepare leaders with the ability to incorporate technology in a digital era effectively.

This study presented a clear picture of e-leadership in higher educational institutions. The next study may examine the factors and all the dimensions of e-leadership that encourage competitiveness in the $21^{\text {st }}$ century.

This research does not only benefit higher education, but it also benefits schools or any organization that could apply this research for sustainable education and developing future human resources.

\section{References}

Antonakis, J., \& Atwater, L. (2002). Leader distance: A review and a proposed theory. The Leadership Quarterly, 13(6), 673-704. doi:10.1016/S1048-9843(02)00155-8

Avolio, B. J., \& Kahai, S. S. (2003). Adding the "e" to e-leadership: How it may impact your leadership. Organizational Dynamics, 31(4), 325-338. doi: 10.1016/S00902616(02)00133-X

Avolio, B. J., Walumbwa, F. O., \& Weber, T. J. (2009). Leadership: Current theories, research, and future directions. Annual Review of Psychology, 60(1), 421-449. doi: 10.1146/annurev.psych.60.110707.163621

Buasuwan, P. (2018). Rethinking Thai higher education for Thailand 4.0, Asian Education and Development Studies, 7(2), 157-173. doi: 10.1108/AEDS-07-2017-0072

Brown, J. S., \& Duguid, P. (2000). The social life of information. Boston, MA: Harvard Business School Press.

Cacheiro-González, M. L., Mata-Benito, P., \& Ubachs, G. (2013). Networked curricula: Fostering transnational partnership in open and distance learning. Open Praxis, 5(2), 179-187. doi: 10.5944/open praxis.5.2.54

Carey, T., \& Trick, D. (2013). How online learning affects productivity, cost and quality in higher education: An environmental scan and review of the literature. Higher Education Quality Council of Ontario, Toronto.

Colfax, R. S., Santos, A. T., \& Diego, J. (2009). Virtual leadership: A green possibility in critical times but can it really work? Journal of International Business Research, $8(2), 133-139$.

EADTU (2016b). Quality assessment for e-learning: A benchmarking approach, $3^{\text {rd }}$ Ed., EADTU, Maastricht. 
Franciosi, S. J. (2012). Transformational leadership for education in a digital culture. Digital Culture and Education, 4(2), 235-247.

Franciosi, S. J. (2012). Transformational leadership for education in a digital culture. Digital Culture and Education, 4(2), 235-247.

Franzenburg, G. (2016). Sustainability by education: How Latvian heritage was kept alive in German exile. Discourse and Communication for Sustainable Education, 7(1), 100-111. doi: 10.1515/dcse-2016-0007

Fullan, M. (2001). Leading in a culture of change. San Francisco, CA: Jossey-Bass.

Ghorbani, S., Jafari, S. E. M., \& Sharifan, F. (2018). Learning to be: Teachers' competences and practical solutions: A step towards sustainable development. Journal of Teacher Education for Sustainability, 20(1), 20-45. doi: 10.2478/jtes-2018-0002

Grenier, R., \& Metes, G. (1995). Going virtual: Moving your organization into the $21^{\text {st }}$ Century. Prentice-Hall, Upper Saddle River, NJ.

Gu, W., \& Surendra, G. (2004). The effect of organizational innovation and information technology on firm performance. International Performance Monitor, 9, 37-51. doi: $10.2139 /$ ssrn.1404689

Hartman, R. J., Johnston, E., \& Hill, M. (2017). Empathetic design: A sustainable approach to school change. Discourse and Communication for Sustainable Education, 8(2), 38-56. doi: 10.1515/dcse-2017-0014

HEFCE. (2012). Collaborations, alliances and mergers in higher education: Consultation on lessons learned and guidance for institutions. Bristol: Higher Education Funding Council for England.

Jones, M., \& Harris, A. (2014). Principals leading successful organizational change: Building social capital through disciplined professional collaboration. Journal of Organizational Change Management, 27(3), 473-485. doi: 10.11.1108/JOCM07-2013-0116

Kearsley, AWH. (1991). Evaluation of the geoid in the Philippines. Unisearch Limited for SAGRIC International.

Kearlsey, G., \& Lynch, W. (1992). Educational leadership in the age of technology: The new skills. Journal of Research on Computing in Education, 25(1), 50-60. doi: 10.1080/08886504.1992.10782032

Matthews, A. W. (2002). Technology leadership at a junior high school: A qualitative case study. Doctoral dissertation, University of Nevada-Las Vegas, USA.

Miedema, S., \& Bertram-Troost, G. (2015). The challenges of global citizenship for worldview education. The perspective of social sustainability. Journal of Teacher Education for Sustainability, 17(2), 44-52. doi: 10.1515/jtes-2015-0010

Milgrom, P., \& Roberts, J. (1990). The economics of modern manufacturing: Technology, strategy, and organization. The American Economic Review, 80(3), 511-528.

Moyle, K. (2005). Computing technologies in school education: Policies and standards and standard policies. Paper presented at the AARE 2005 Conference, Sydney.

OECD/UNESCO. (2016). Education in Thailand: An OECD-UNESCO perspective, reviews of national policies for education. OECD Publishing, Paris.

Office of the Higher Education Commission. (2010). Higher education in Thailand development for better living. The Report of National Conference in 2010, OHEC.

Office of the Higher Education Commission. (2012). The eleventh higher education development plan (2012-2016). Retrieved from http://www.mua.go.th/user/bpp/ developplan. (in Thai) 
Office of the Higher Education Commission. (2017). The twelfth higher education development plan (2017-2021). Retrieved from http://www.mua.go.th/users/bpp/ developplan. (in Thai)

Office of the Permanent Secretary, Ministry of Science and Technology. (2017). The digital action plan 2017-2021. Retrieved from http://cio.most.go.th

Office of the Secretary of the House of Representatives. (2016). Digital economy and social development plan (draft): Digital Thailand. Retrieved from https://www.etda. or.th/content_files/2/files/00003.pdf

ONEC. (1999). Hope for a better Thailand. Thailand: Office of the national education commission. Retrieved from http://www.edthai.com/reform/nov28a.htm

Online Learning Task Force. (2011). Collaborate to compete: Seizing the opportunity of online learning for UK higher education. HEFCE, London.

Ottestad, G. (2013). School leadership for ICT and teachers' use of digital tools. Nordic Journal of Digital Literacy, 8(01-02), 107-125.

Raskin, M. S. (1994). The delphi study in field instruction revisited: Expert consensus on issues and research priorities. Journal of Social Work Education, 30(1), 75-89.

Rayens, M. K., \& Hahn, E. J. (2000). Building consensus using the policy delphi method. Policy, Politics \& Nursing Practice, 1(4), 308-315. doi:10.1177/15271544000010 0409

RMIT University. (2017). About RMIT. RMIT University. Retrieved from www.rmit. edu.au

Sheninger, E. (2014). Digital leadership: Changing paradigms for changing times. Thousand Oaks, CA: Corwin A Sage Company.

Siegel, C., \& Claydon, J. (2016). Innovation in higher education: The influence of classroom design and instructional technology. I-manager's Journal on School Educational Technology, 12(2), 24-33. doi: 10.26634/ jsch.12.2.8216

Svalfors, U. (2017). Education for sustainable development and multidimensional implementation. A study of implementations of sustainable development in education with the curriculum of upper secondary school in Sweden as an example. Discourse and Communication for Sustainable Education, 8(2), 114-126. doi:10.1515/dcse2017-0020

Thairath Online. (2014). Push forward master plan of educational technology, 9 January 2014. Retrieved from http://www.thairath.co.th/content/394701

Vanitcharearnthum, V. (2017). Top income shares and inequality: Evidences from Thailand. Kasetsart Journal of Social Sciences, 1-7. doi:10.1016/j.kjss.2017.07.010

Yee, D. L. (2000). Images of school principals' information and communications technology leadership. Journal of Information Technology for Teacher Education, 9(3), 287-302.

Zaccaro, S. J., \& Bader, P. (2003). E-leadership and the challenges of leading e-teams: Minimizing the bad and maximizing the good. Organizational Dynamics, 31(4), 377-387. doi: 10.1016/S0090-2616(02)00129-8

Correspondence regarding this article should be addressed to Kittiya Sathithada and Poschanan Niramitchainont, Faculty of Social Science and Humanities, Mahidol University, Thailand. Email: vevor@hotmail.com 